\title{
A Comparative Study on Physical Activity, Dietary Habits, and Physical Strength According to Body Fat Groups in College Students
}

\author{
Mi Ryeong Song \\ Associate Professor, College of Nursing, Gachon University \\ miryeong@gachon.ac.kr
}

\begin{abstract}
The purpose of this study was to analyze the differences in physical activity, dietary habits, and physical strength between college students with normal and high body fat. This is a comparative study. In total, 78 people aged 20-29 consented to participate in the study: 48 in the normal body fat group and 30 in the high body fat group. Participants were surveyed on general and health-related characteristics, physical activities, and dietary habits through a questionnaire. Body fat, body mass index, muscular strength, flexibility, and lung capacity were measured. The differences in general and healthrelated characteristics, physical activity, dietary habits, and physical strength between the two groups were examined with the $\chi^{2}$-test and an independent t-test using SPSS 21.0. There were no significant differences on gender, perceived health, and interest in health between the two groups. There was a significant difference in the awareness of body shape, intensity, type and frequency of exercise, muscular strength, flexibility, and lung capacity between two groups. There were no differences in dietary habits between the two groups. The result of this study indicates that physical activity and physical strength have a more direct relationship with body fat than dietary habits. Constant interest and management of body fat is required, especially with regard to physical activity and physical strength.
\end{abstract}

Keywords: physical activity, dietary habit, body fat, college students

\section{Introduction}

\subsection{The Necessity of Research}

There are many indicators of obesity, such as weight, body mass index (BMI), body fat, arm circumference, thickness of the triceps, waist-to-hip ratio, etc. Traditionally, BMI, which uses weight and height, was widely used as an indicator of obesity. However, there is an aspect that weight or BMI does not accurately reflect a physical constitution. Since obesity, particularly abdominal obesity, is increasing due to changes in lifestyle habits, the interest in body fat is growing. Furthermore, with the development of diagnostic techniques enabling accurate measurement of percentage body fat, body fat has gradually been more widely used as an indicator of obesity. It has been reported that body fat is a good indicator of obesity [1], and is interrelated with health conditions [2]. Since body fat is known to be a factor interrelated with heart disease, high blood pressure, diabetes, etc., there is a need for regular monitoring.

Meanwhile, it is known that physical activity and dietary control are essential for the management of obesity and health. Physical activities prevent or control obesity and improve health conditions [3]. Diet is also considered essential for preventing and controlling obesity [4]. Although physical activities and dietary control are included in many health promotion programs, busy modern lifestyles disturb implementation. 
Analyzing whether physical activity or diet is more important can provide the public with a wider range of choices and increase the possibility of performance. Some studies have verified the differences between physical activity and dietary habits according to BMI [5]; however, there are almost no studies verifying the differences according to body fat.

Body fat has been reported to negatively affect physical strength [6]. Also, a decline in physical strength is interrelated not only with the health of an individual, but also with a decline in business productivity. In the precedent study, it was reported that as body fat increases, muscular endurance and flexibility decline [7]; this shows that management of body fat is an important factor for fitness management. This study intends to verify the differences in physical activities, dietary habits, and physical strength between a normal body fat group and a high body fat group. This will allow verification of which factor, physical activities or dietary habits, has more influence on body fat, and on how body fat affects physical strength. This will also provide important data for obesity and health management, and will provide supporting data on the relations between body fat ratio, physical activities, dietary habits, and physical strength.

\subsection{Purpose of Study}

This study was conducted to analyze the differences in physical activity, dietary habits, and physical strength between college students with normal body fat and those with high body fat. Ultimately, it attempts to provide relevant data for developing health promotion programs.

\section{Methods}

\subsection{Research Design}

This is a comparative study to analyze the differences in physical activities, dietary habits, and physical strength between a normal body fat group and a high body fat group.

\subsection{Research Participants}

Male and female college students aged 20-29 years with no physical activity restrictions who consented to participate were included in the study. When estimated based on the independent t-test by using $G^{*}$ power with medium effect size of 0.6 , power .80 at the .05 significance level, the total number of subjects required was 72 (36 in each group). Among the 78 subjects who wished to participate, 48 were in the normal body fat group and 30 were in the high body fat group. The verification power was .82 . Body fat percentage was measured using an electronic body fat analyzer (Omron, HBF214, Kyoto, Japan). Body fat percentages of $14 \sim 18 \%$ for men and $15 \sim 30 \%$ for women were classified as normal; more than $18.1 \%$ for men and more than $30.1 \%$ for women were classified into the high body fat group [8].

\subsection{Data Collection}

In September 2013, at the healthcare center of a university, the subjects who wished to participate in this study were surveyed on general and health-related matters through a questionnaire. Then body fat, BMI, muscular endurance, flexibility, and lung capacity were measured. The questionnaire was filled out directly in person. Body measurements were measured by trained research assistants, each of whom took charge of one item. Filling out the questionnaire and taking the measurements took around 20 minutes. Body fat and BMI were measured using an electronic scale. 


\subsection{Research Tools}

2.4.1. General and Health-Related Characteristics: Gender and perceived health condition, the degree of interest in health, awareness of body shape and BMI were included.

2.4.2. Physical Activities: The tools used are the questions on physical activities of the national health and nutrition survey of 2008, implemented by the Ministry for Health, Welfare, and Family Affairs and the Centers for Disease Control and Prevention, modified and supplemented by Cho [9]. In this tool, vigorous physical, moderate physical, walking, stretching and muscular endurance activities are evaluated based on the following responses: "never"( 0 points), "1 2 days"( 1 point), “3 4 days"( 2 points), "5 6 days"( 3 points), and "everyday"(4 points).

For vigorous physical activities, the question was "During the past week, for how many days did you do very strenuous or vigorous physical activities (for example: running, hiking, soccer, basketball, jump rope, high-speed cycling) for more than 10 minutes?" For moderate physical activities, the question was "During the past week, for how many days did you do moderate physical activities that were a little more strenuous than usual (for example: volleyball, badminton, table tennis, slow swimming) for more than 10 minutes?' For walking, the question was "During the past week, for how many days did you walk at least more than 10 minutes at a time including walking to and from school walking for travel and exercise?" For stretching, the question was "During the past week, for how many days did you do flexibility exercise such as stretching, free gymnastics?" For muscular endurance activities, the question was "During the past week, for how many days did you do muscular exercises such as push-ups, sit-ups, dumbbells, barbells?"

2.4.3. Dietary Habits: Dietary habits were measured through eating behavior and food intake.

Eating behavior. The tool developed by Cho [9] was modified and supplemented for this study. This tool has eight questions evaluating imbalanced diet, going without a meal, overeating, having a late-night snack, eating spicy or strong-tasting foods, etc. For the evaluation method, a 5-point Likert scale of "never", "little", "somewhat", "much", "a great deal" was used; the higher the score, the more undesirable the dietary behavior. In this study, Cronbach's alpha was .71.

Food intake. It was to evaluate the amount of intake from the fivebasic food groups, and the questions were as follows: "How many times a day do you eat rice, flour, or bread?" (Food group I), "How many times a day do you eat vegetables or fruits?" (Food group II), "How many times a day do you eat meat, fish, eggs, or beans?" (Food group III), "How many times a day do you eat milk and dairy products?" (Food group IV), and "How many times a day do you eat fat and oils (cooking oil, sesame oil, butter, or mayonnaise) and sugars (sugar or carbonated drinks)?" (Food group V). For each food group, the response was the number of intakes each day ( 0 time, 1 time, 2 times, more than 3 times).

2.4.4. Physical Strength: Muscular strength, flexibility, and lung capacity were included. For muscular strength, the superior arm's strength was measured (in $\mathrm{kg}$ ) by using a grip force measuring apparatus (Tanita 6104, Tokyo, Japan). For flexibility, the subjects had to bend forward at the waist on the measuring stand and the distance that the hands extended below the feet was measured (in $\mathrm{cm}$ ). For lung capacity, using an inspirometer, the duration of time for which a ball was maintained floating which indicated breathing capacity $(700 \mathrm{cc})$ was measured (in seconds). 


\subsection{Data Analysis}

In analyzing the collected data, the difference between the two groups in regard to general characteristics and health-related characteristics was examined with the $\chi^{2}$-test and independent t-test. The difference in physical activity, dietary habits, and physical strength between the two groups was examined with the independent t-test using SPSS 21.0 (IBM Corp., Armonk, NY, USA).

\section{Results}

\subsection{Differences on General Characteristics, Health-Related Characteristics and Physical Strength According to Body Fat Group}

There was no significant difference of gender $\left(\chi^{2}=.021, p=1.000\right)$ between the normal body fat group and the high body fat group. Perceived health $\left(\chi^{2}=1.67, p=.444\right)$ and interest in health $\left(\chi^{2}=3.56, p=.188\right)$ also had no significant differences. There was a significant difference on the awareness of body shape $\left(\chi^{2}=25.01, p=.000\right)$. The mean BMI was 21.3 in the normal body fat group and 25.5 in high body fat group, a significant difference between the two groups $(\mathrm{t}=-6.14, p=.000)$. There were also significant differences in muscular strength $(\mathrm{t}=3.47, p=.001)$, flexibility $(\mathrm{t}=2.20, p=.031)$, and lung capacity $(\mathrm{t}=2.04, p=.047)$; all factors were higher in the normal body fat group than in the high body fat group.

Table 1. Differences in General Characteristics, Health-Related Characteristics and Physical Strength of the Two Body Fat Groups

\begin{tabular}{|c|c|c|c|c|}
\hline Variables & Categories & $\begin{array}{r}\text { Normal body fat } \\
\mathrm{n}(\%)\end{array}$ & $\begin{array}{r}\text { High body fat } \\
\mathrm{n}(\%)\end{array}$ & $\chi^{2} / t(p)$ \\
\hline \multirow{2}{*}{ Gender } & Male & $28(58.3)$ & $18(60.0)$ & $.021(1.000)$ \\
\hline & Female & $20(41.7)$ & $12(40.0)$ & \\
\hline \multirow{3}{*}{ Perceived health } & $\mathrm{Bad}$ & $7(14.6)$ & $6(20.0)$ & $1.67(.444)$ \\
\hline & Moderate & $28(58.3)$ & $13(43.3)$ & \\
\hline & Good & $13(27.1)$ & $11(36.7)$ & \\
\hline \multirow{3}{*}{ Health interest } & Never & $2(4.2)$ & $5(16.7)$ & $3.56(.188)$ \\
\hline & Somewhat & $23(47.9)$ & $12(40.0)$ & \\
\hline & A great deal & $23(47.9)$ & $13(43.3)$ & \\
\hline \multirow{3}{*}{$\begin{array}{l}\text { Awareness of body } \\
\text { shape }\end{array}$} & Thin & $7(14.6)$ & $0(0.0)$ & $25.01(.000)$ \\
\hline & Moderate & $30(62.5)$ & $6(20.0)$ & \\
\hline & Obese & $11(22.9)$ & $24(80.0)$ & \\
\hline BMI & & $21.30 \pm 2.06$ & $25.46 \pm 3.34$ & $-6.14(.000)$ \\
\hline $\begin{array}{l}\text { Muscular } \\
\text { strength }(\mathrm{kg})\end{array}$ & & $42.42 \pm 11.73$ & $31.00 \pm 15.47$ & $3.47(.001)$ \\
\hline Flexibility $(\mathrm{cm})$ & & $14.22 \pm 8.44$ & $9.32 \pm 11.15$ & $2.20(.031)$ \\
\hline Lung capacity(sec) & & $1.74 \pm .30$ & $1.55 \pm .46$ & $2.04(.047)$ \\
\hline
\end{tabular}

\subsection{Differences on Physical Activity According to Body Fat Group}

There were differences on intensity, type and frequency of exercise between the two groups in vigorous physical activities $(\mathrm{t}=2.34, p=.022)$, moderate physical activities $(\mathrm{t}=3.39, p=.001)$, stretching $(\mathrm{t}=2.38, p=.020)$, and muscular endurance activities $(\mathrm{t}=2.55$, $p=.013)$. There was no difference on walking $(\mathrm{t}=-.38, p=.707)$ between the two groups, 


\subsection{Differences on Dietary Habits According to Body Fat Group}

There were no differences in eating behavior $(\mathrm{t}=1.37, p=.175)$ and food intake. No differences were found for rice, flour, or bread (Food group I) ( $\mathrm{t}=-1.06, p=.291)$; vegetables or fruit (Food group II) ( $\mathrm{t}=-.85, p=.398)$; meat, fish, eggs, or beans (Food group III) ( $\mathrm{t}=-.89, p=.378)$; milk and dairy products (Food group IV) $(\mathrm{t}=1.57, p=.120)$; and fat, oils and sugars (Food group V) $(\mathrm{t}=1.57, p=.120)$ according to body fat group.

Table 2. Differences in Physical Activity of the Two Body Fat Groups

\begin{tabular}{ccrrr}
\hline \multirow{2}{*}{ Variables } & Categories & $\begin{array}{r}\text { Normal body fat } \\
\text { Mean }( \pm \text { SD) }\end{array}$ & $\begin{array}{r}\text { High body fat } \\
\text { Mean }( \pm \text { SD) }\end{array}$ & $t(\mathrm{p})$ \\
\hline \multirow{3}{*}{$\begin{array}{c}\text { Physical activity } \\
\text { (frequency/week) }\end{array}$} & Vigorous & $2.06 \pm 1.17$ & $1.53 \pm .82$ & $2.34(.022)$ \\
\cline { 2 - 5 } & Moderate & $2.02 \pm 1.14$ & $1.37 \pm .56$ & $3.39(.001)$ \\
\cline { 2 - 5 } & Walking & $3.96 \pm 1.25$ & $4.07 \pm 1.20$ & $-.38(.707)$ \\
\cline { 2 - 5 } & Stretching & $2.52 \pm 1.38$ & $1.80 \pm 1.16$ & $2.38(.020)$ \\
\hline & Muscular & $2.31 \pm 1.29$ & $1.60 \pm 1.04$ & $2.55(.013)$ \\
\hline
\end{tabular}

Table 3. Differences in Dietary Habits of the Two Body Fat Groups

\begin{tabular}{lcrrr}
\hline \multicolumn{1}{c}{ Variables } & categories & $\begin{array}{r}\text { Normal body fat } \\
\text { Mean }( \pm \text { SD) }\end{array}$ & $\begin{array}{r}\text { High body fat } \\
\text { Mean }( \pm \text { SD) }\end{array}$ & t(p) \\
\hline Dietary habit & Group I & $2.39 \pm .52$ & $2.23 \pm .46$ & $1.37(.175)$ \\
\hline \multirow{2}{*}{$\begin{array}{l}\text { Food intake } \\
\text { frequency/day) }\end{array}$} & Group II & $1.69 \pm .69$ & $1.87 \pm .78$ & $-1.06(.291)$ \\
\cline { 2 - 5 } & Group IV & $1.19 \pm .87$ & $1.37 \pm .96$ & $-.85(.398)$ \\
\cline { 2 - 5 } & Group V & $1.38 \pm .76$ & $1.53 \pm .78$ & $-.89(.378)$ \\
\hline & & $1.25 \pm .98$ & $.90 \pm .92$ & $1.57(.120)$ \\
\hline
\end{tabular}

\section{Discussion}

In this study, for the high body fat group, there were more negative responses regarding perceived health conditions, and interest in health, yet there were no statistically significant differences. This owes to the fact that the subjects are in early adulthood before the occurrence of particular diseases associated with high body fat, and are not yet aware of health problems. With respect to the awareness of body shape, $80 \%$ of the participants in the high body fat group considered themselves to be obese; hence, there were significant differences between the two groups. In the normal body fat group, BMI was in the normal range (21.3), and in the high body fat group, it was in the range pertinent to obesity (25.5); hence, body fat and BMI classification coincided. Therefore, subjects in the high body fat group were actually in the state of obesity by the BMI standard, and were aware of their obesity.

In this study, there were differences in physical activities, but no differences in dietary habits between the normal body fat group and the high body fat group. This indicates that physical activities have a more direct bearing on body fat management. The only category that did not show between-group differences was walking, which is probably because, due to large university campuses, students living within a university usually have to walk for more than 10 minutes per day. In the case of walking, according to the Physical Activity Guidelines for Americans, more than 30 minutes of active walking is advised to obtain the effect of moderate intensity [10]; thus, there will be differences if days when participants 
walked for more than 30 minutes are compared.

The fact that there are no differences in dietary habits, including eating behavior and food intake, between the two groups indicates that, since obesity is closely linked to heredity [11], the point that there are people who constitutionally do not gain weight despite overeating should be considered. Regarding diet, since an individual's hereditary or family history is important, calorie regulations should be necessary for subjects with a predisposition to obesity. Generally, interventions for consuming healthy food are considered important for adequate nutrient intake. Although there were no significant differences between the two groups, milk and dairy products were not consumed even once a day in the high body fat group. As milk and dairy products are important sources of calcium, it could be related to a more frequent occurrence of osteoporosis in people with high body fat [12]; hence, further research on the relevance of this finding will be necessary.

In this study, muscular strength, flexibility, and lung capacity were significantly higher in the normal body fat group, who were better in physical strength compared to the high body fat group. In a precedent study, muscular strength [13], flexibility [14], and lung capacity [15] were also reported to be low in the high body fat group. This might be due to difference of physical activity between the two groups. Muscle mass and fat mass are useful biomarkers of physical activity [16] and muscle mass and muscle strength are positively correlated [17], that muscular strength was greater in the normal body fat group than in the high body fat group is not unusual. Flexibility indicates elasticity of the body, and it is thought to be increased in the normal body fat group due to higher levels of body protein, especially elastic proteins. Also, in those with high body fat, waist circumference generally increases. Thus, it is possible that flexibility was lower in the high body fat group since flexibility was measured by bending forward at the waist.

With respect to lung capacity, our findings coincide with those of a previous study that reported that the lung capacity declines as the body fat percentage increases [15, 18]. Accumulation of fat in the abdomen decreases the volume of the chest cavity and declines muscular strength of the respiratory muscles. Physical strength is an important indicator of health, and it is related to the productivity of an individual; these findings indicate that the normal body fat group can lead a healthier lifestyle with better quality of life than the high body fat group. Actually, physical strength has been reported to play an important role in the quality of life [19]. The differences in physical strength in early adulthood, prior to the occurrence of changes in physical health caused by body fat, could escalate with age [20]. Body fat has a great effect on a person's health; hence, it requires constant focus and management always.

\section{References}

[1] L. Cuppari, "Diagnosis of obesity in chronic kidney disease: BMI or body fat?", Nephrol Dial Transplant, vol. 28, supple 4, (2013), pp. 119-121.

[2] N. Wijnstok, T. Hoekstra, E. Eringa, Y. Smulders, J. Twisk and E. Serne, "The relationship of body fitness and body fat distribution with microvascular recruitment: The Amsterdam Growth and Health Longitudinal Study”, Microcirculation, vol. 19, no. 3, (2012), pp. 273-279.

[3] H. Mohamadian and A. R. Ghannaee, "Factors predicting the physical activity behavior of female adolescent: a test of the health promotion model", Prev Med Public Health, vol. 47, no. 1, (2014), pp. 64-71.

[4] I. Kondo, K. Funahashi, M. Nakamura, T. Ojima, K. Yoshita and Y. Nakamura, "Association between Food Group Intake and Serum Total cholesterol in the Japanese Population: Nippon DATA 80/90", Journal of Epidemiol, vol. 20, supple 3, (2010), pp. S576-S581.

[5] L. Basterfield, A. R. Jones, K. N. Parkinson, J. Reilly, M. S. Pearce, J. J. Reilly, A. J. Adamson and Gateshead Millennium Study Core Team, "Physical activity, diet and BMI in children aged 6-8 years : a cross-sectional analysis", BMJ Open, vol. 4, no. 6, (2014).

[6] K. Minematsu, R. Kawabuchi, H. Okazaki, H. Tomita, T. Tobina, T. Tanigawa and N. Tsunawake, "Physical activity cut-offs and risk factors for preventing child obesity in Japan", PediatrInt, doi: 10.1111/ped.12446, (2014). 
[7] N. Tanaka and K. Fujii, "Physical strength in boys with different levels of fat accumulation and BMI : Report on South Korean Junior high school boys", J Hum Ergol, vol. 41, (2012), pp. 31-40.

[8] M. J. Kim, M. S. Song and H. A. Kim, "Nursing Application of Nutrition and Diet", Edited M. J. Kim, Jungmungak, Seoul, (2009), South Korea.

[9] J. Cho, "A study on dietary life style, health and psychological status of university students by dietary habit and BMI, development health dietary life style program", Doctoral dissertation, Ulsan University, Ulsan, Korea, (2011).

[10] Office of Disease Prevention and Health Promotion, "Physical Activity Guidelines for Americans", Retrieved January 7, 2014, from http://www.health.gov/paguidelines/guidelines/, (2011).

[11] T. Temelkova-Kurktschiev and T. Stefanov, "Lifestyle and genetics in obesity and type 2 diabetes", Exp Clin Endocrinol Diabetes, vol. 120, no. 1, (2012), pp. 1-6.

[12] P. Y. Liu, J. Z. Ilich, K. Brummel-Smith and S. Ghosh, "New insight into fat, muscle and bone relationship in women: determining the threshold at which body fat assumes negative relationship with bone mineral density", Int J Prev Med, vol. 5, no. 11, (2014), pp. 1452-1463.

[13] K. Crawford, K. Fleishman, J. P. Abt, T. C. Sell, M. Lovalekar, T. Nagai, J. Deluzio, R. S. Rowe, M. A. McGrail and S. M. Lephart, "Less body fat improves physical and physiological performance in army soldiers", Mil Med, vol. 176, no. 1, (2011), pp. 35-43.

[14] E. G. Artero, V. Espana-Romero, F. B. Ortega, D. Jimenez-Pavon, J. R. Ruiz and G. Vicente-Rodriguez, "Health-related fitness in adolescents : underweight, and not only overweight, as an influencing factor. The AVENA study", Scand J Med Sci Sports, vol. 20, no. 3, (2010), pp. 418-427.

[15] A. R. Joshi, R. Singh and A. R. Joshi, "Correlation of pulmonary function tests with body fat percentage in young individuals", Indian J PhysiolPhamacol, vol. 52, no. 4, (2008), pp. 383-388.

[16] G. Palacios, R. Pedrero-Chamizo, N. Palacios, B. Maroto-Sanchez, S. Aznar and M. Gonzalez-Gross, "Biomarkers of physical activity and exercise", Nutr Hosp, vol. 31, (2015), pp. 237-244.

[17] L. Chen, D. R. Nelson, Y. Zhao, Z. Cui and J. A. Johnston, "Relationship between muscle mass and muscle strength, and the impact of comorbidities: a population-based, cross-sectional study of older adults in the United States", BMC Geriatr, doi: 10.1186/1471-2318-13-74, vol. 13, (2013).

[18] E. Ceylan, A. Comlekci, A. Akkoclu, C. Ceylan, O. Itil, G. Ergor and S. Yesil, "The effects of body fat distribution on pulmonary function tests in the overweight and obese", South Med J, vol. 100, no. 1, (2009), pp. 30-35.

[19] M. J. Benton, J. L. Alexander and J. D. Holland, "Relationship between strength, function, and quality of life in older adults with chronic lung disease: is there an influence of gender?", Journal of Cardiopulm Rehabil Prev, vol. 34, no. 2, pp. 143-149.

[20] M. R. Song, "An Analysis of the Physical Activity and Eating Behavior of College Students", Proceedings of the $6^{\text {th }}$ international workshop on Health care and Nursing, Jeju, South Korea, Advanced Science and Technology Letters, vol. 88, (2015) April 15-18, pp. 145-148.

\section{Author}

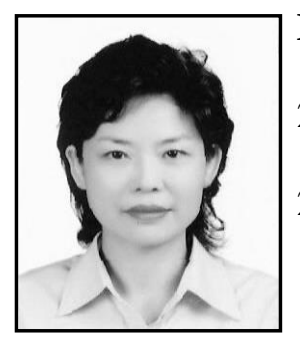

Mi Ryeong Song

1999. 8: Ph. D in Nursing, Seoul National University, Korea

2006. 9- 2014. 8: Associate Professor, Department of Nursing, Hoseo University, South Korea

2014. 9 - Present: Associate Professor, College of Nursing, Gachon University, South Korea 
International Journal of Bio-Science and Bio-Technology

Vol.7, No.5 (2015) 